\title{
Contraceptive Behavior Among Unmarried Young Women: A Theoretical Framework for Research
}

\author{
Constance A. Nathanson \\ Johns Hopkins University \\ Marshall H. Becker \\ University of Michigan
}

Adoption of the most effective methods of contraception requires individual decision-making and negotiation with contraceptive providers. In order to take account of both behavioral elements, a twodimensional framework for understanding contraceptive adoption and continuation by unmarried young is proposed, incorporating a "socialpsychological model" of individual decision-making and an "interpersonal model" of factors affecting provider-client interaction. The social-psychological model is based on an earlier value-expectancy theory of behavior motivation as applied to health-related behaviors. The interpersonal model is derived from conflict-bargaining perspectives on professional-client interaction; it is suggested that expectations for this interaction are based on a limited number of internalized "models": the "professional"; the "bureaucratic"; the "commercial"; and the

Preparation of this paper was supported in part by Grant Number RO1 HD 13623 from the Center for Population Research, National Institute of Child Health and Human Development. Dr. Nathanson is Associate Professor, Department of Population Dynamics, School of Hygiene and Public Health, The Johns Hopkins University. Dr. Becker is Professor, Department of Health Behavior and Health Education, School of Public Health, The University of Michigan. Requests for reprints should be addressed to Dr. Nathanson, Department of Population Dynamics, Johns Hopkins University School of Hygiene and Public Health, 615 North Wolfe Street, Baltimore, MD 21205.

'Readers interested in the apendization of specific variables may write to the senior author for copies of research instruments based on the theoretical framework described in this paper. Space limitations do not permit a discussion of aperational issues in the paper itself. 
"parental." Insofar as client and professional "models"disagree, communication may break down and client understanding and/or acceptance of provider advice cannot be assured. The components of the social-psychological and interpersonal models are described in detail, and a combined framework is proposed.

The majority of pregnancies among unmarried young women are unintended and could be substantially reduced in number by consistent use of contraception; yet close to two-thirds of sexually active young women in the United States are either nonusers or sporadic users of contraceptive methods (Zelnik \& Kantner, 1980). The reasons for erratic contraceptive use when pregnancy is not intended are unclear; however, the consequences of such behavior are potentially most serious when the partners are young and unmarried (Card \& Wise, 1978; Trussell \& Menken, 1978).

Although identification and measurement of factors associated with contraceptive continuation have long been issues of concern, development of a substantive framework on which to base explanation and prediction of variation in contraceptive behaviors has lagged behind accumulation of data (Karr, 1971); Bracken \& Kasl, 1973), and Katatsky (1977) also notes that the dependent variables are often unclearly specified, either conceptually or operationally. This paper will propose a theoretical framework to account for variations in contraceptive continuation among unmarried young women, a framework explicitly designed to be employed as the basis for empirical research.

\section{CONCEPTUAL AND OPERATIONAL ISSUES}

Studies of contraceptive behavior have used a wide variety of dependent variable indices, ranging from determination of the individual's "intention to use" contraception at an unspecified future time (Jaccard \& Davidson, 1972) through whether or not contraception was "ever used" (e.g., Akpom, Akpom, \& Davis, 1976), to the calculation of contraceptive continuation rates using life table methods (e.g., Ricketts, 1973; Einhorn, et al., 1977; Phillips, 1978). With few exceptions (McCalister \& Thiessen, 1970; Bracken \& Kasl, 1973), students of contraceptive behavior have not been concerned with the conceptual distinctions among these 
different indices, and almost no attention has been given to the possibility that such behavior as initial adoption of a contraceptive method, continued use of a method, and clinic attendance may each be predicted by quite different sets of variables. Prior to any attempt at specification of predictor variables, however, it is essential to clarify the nature of the behavior that is being predicted.

"Contraceptive behavior," as the term is employed here, encompasses a set of activities including, at a minimum: identification of a current or potential problem (possible pregnancy); search for and discovery of one or more solutions to this problem; and adoption of a particular solution. Each of these activities can be more or less complex, depending on the circumstances. For example, identification of a current or potential problem requires that the meaning of sexual intercourse in relation to pregnancy be consciously articulated; that intercourse be anticipated to occur or recur; that possible pregnancy be perceived as an issue requiring overt attention; and that pregnancy be evaluated as an undesirable outcome (a "problem"). Although in practice we tend to assume that recognition of the problem is made by the person to whom it may occur (the female partner, in the case of pregnancy), in theory this identification can be made by anyone who is in a position to be aware of the possibilities (e.g., the male sexual partner, the girl's mother, close girlfriends, the family physician). Furthermore, who identifies the problem may have significant implications for what, if any, action is subsequently taken.

Although the sets of activities that are encompassed by the term "contraceptive behavior" appear to form a logical sequence, it should be emphasized that this sequence may be interrupted at any point without proceeding to the (apparently logical) next step. Problem identification does not invariably lead to the search for a solution. The search process (which includes evaluation of alternative solutions) may or may not result in adoption of a particular solution; alternative solutions may be tried and discarded. In addition, a salient characteristic of most currently available "solutions" to the pregnancy problem is that one or more of the sets of activities specified above must occur repeatedly if the solution is to be effective.

Insofar as prior research has attempted to view contraceptive behavior from a theoretical (as opposed to a purely descriptive) perspective, the primary focus of attention has been on the set of 
activities that intervene between problem identification and adoption of a solution: the search, discovery, and evaluation process. This dimension of contraceptive behavior has been conceptualized by Fishbein and others (Fishbein, 1972; see also Jaccard \& Davidson, 1972; Fishbein \& Jaccard, 1973; Jaccard \& Davidson, 1976 and the review by Adler, 1979) in terms of psychological decision-making models, in which choice among alternative behaviors ("solutions" in the phraseology employed here) is based on the consequences of these behaviors as defined by the ratio of perceived advantages to perceived disadvantages. Although certain dimensions of contraceptive behavior may be approached quite usefully in terms of these models, most of the specific models which have been employed contain at least two important deficiencies: they assume the identification by the potential user of a problem or issue requiring that some contraceptive decision needs to be made, and they fail to take account of the adoption process itself, as it is differentially affected by the attributes of specific contraceptive methods. [However, Luker's (1975) model of contraceptive risk-taking does refer explicitly to the "psychic costs" of acknowledging and planning for sexual activity.]

Adoption of a specific contraceptive method can be conceptualized as an innovation-decision insofar as it involves initiating behavior that is "perceived as new" by the individual, a reasonable assumption in the context of research on unmarried young women (Rogers \& Shoemaker, 1971). As emphasized in recent literature (Nathanson \& Morlock, 1980), the attributes of the innovation itself are potentially of major importance in determining whether or not adoption occurs and/or is sustained over time. Although attention has been called to the relative difficulty in obtaining adoption of contraception as such (Suchman, 1963), and although the potential consequences for adoption of specific method attributes have been noted sporadically (Rogers, 1973) little systematic attention has been paid to the different adoption processes required by different methods.

Alternative contraceptive "solutions" to the problem of pregnancy prevention vary widely in the adoption processes with which they are associated; for example, they differ with respect to who uses the method, the individual initiative required for adoption, the complexity of the pathways to adoption, and the complexity (intellectual, technological, interpersonal) of use. 
Although all of these characteristics are potentially important, one of the most striking differences among methods is in the complexity of pathways to adoption - i.e., in the extent to which adoption requires negotiating channels external to the actors directly involved. Zaltman \& Lin (1971) have identified this attribute of an innovation as "the number of gatekeepers" involved before adoption can take place. Contraceptive methods can be arrayed along this dimension from, for example, withdrawal, which demands no interaction with third parties, to such methods as the diaphragm, the IUD, and the pill, all of which require (at least in the United States) entry into the health care system and interaction with (usually several) medical and allied personnel.

Research on the adoption of "modern" medical methods of contraception from an innovation perspective (cf. Rogers, 1973) has focused heavily on the actions of health professionals and on the characteristics of organized programs. Adoption is seen as varying with the effectiveness of "change agents" and with the nature of their communications, rather than with the characteristics of individual adopters. By contrast, research in the tradition of behavior motivation has focused on the stages prior to actual adoption, and has employed individual decision-making models in which the potential adopter weighs the advantages and disadvantages of alternative behaviors open to him or her. These are not, of course, mutually-exclusive approaches; a comprehensive account of contraceptive behavior (at least of behavior that culminates in the adoption and continued use of "modern" methods) will need to include explanatory variables from both frameworks (cf. Bracken \& Kasl, 1973). The remainder of this paper attempts the development of such a two-dimensional (i.e., "psychosocial" and "interpersonal") approach to the explanation of contraceptive behavior among unmarried young women.

\section{CONTRACEPTIVE ADOPTION: PSYCHOSOCIAL VARIABLES}

Several investigators (Rogers, 1973; D'Onofrio, 1973; Bracken, 1976; Katatsky, 1977) have observed that contraceptive behavior has elements in common with more conventional "preventive health behavior" (for example, obtaining immunizations, screening tests, check-ups) and that an existing decision model developed to 
account for the latter behavior might fruitfully be applied to the former behavior as well. This "Health Belief Model" (HBM), like the decision-making models referred to earlier, is based on more general theories of behavior motivation; however, unlike these models, it includes as explicit and separable components: the value to the individual of the goal ("valence") toward which behavior is directed; and the individual's estimate of the likelihood that the behavior in question will result in achieving that goal. Placing decision-making within a goal-attainment framework markedly facilitates the specification of "costs" and "benefits" associated with alternative contraceptive choices, and also provides a vehicle for including the "problem identification" stage of contraceptive behavior directly within the model as a set of variables influencing the value of the goal of avoiding pregnancy.

A thorough contrast of the HBM with other models is beyond the scope of this article; such comparisons are, however, available elsewhere (cf. Maiman \& Becker, 1974; Becker et al., 1977). The rationale for employing the $\mathrm{HBM}$ as the organizing rubric for the psychosocial approach includes three considerations. First, the model's core dimensions are derived from a well-established body of psychological theory, and its focus on the valence of a goal, subjective probability of attainment, and motivation make it very similar to older models of decison-making under uncertainty, (reviewed in Maiman \& Becker, 1974) and to the more recent works of Fishbein (1972) and Kothandapani (1972). For example, Fishbein's (1972) model specifies two factors as the major determinants of behavioral intentions: beliefs about the consequences of performing the behavior and the value of these consequences for the individual (i.e., subjective probability and valence), and perception of the behavioral expectations that various reference groups or other individuals hold (i.e., normative beliefs and motivations to comply with them). Similarly, Kothandapani's (1971) study linking behavioral intentions to contraceptive behavior includes variables central to the HBM. Second, the HBM's variables provide potentially-intervenable (i.e., modifiable) bases for intervention strategies to improve levels of contraceptive use. Third, it is the model which has been most widely employed and empirically assessed, especially with regard to the undertaking of preventive health actions.

In the HBM, "valence" is represented by the individual's belief in his or her susceptibility to a disease condition, and by the perceived seriousness of the condition if contracted; "likelihood of 
goal attainment ${ }^{\prime \prime}$ is represented by the individual's evaluation of the benefits of preventive action weighed against the perceived barriers to undertaking that action. Although the HBM has seldom been explicitly applied to contraceptive behavior, many of the variables emphasized in earlier contraception studies appear to have operationalized one or more HBM dimensions. The relationship of these variables to the model will be examined under three headings: value of the goal; the woman's estimate that her actions will achieve the goal; and additional predisposing and enabling factors.

\section{Value of the Goal}

Rosenstock (1974) points out that, from its inception, the HBM has had "a clearcut avoidance orientation; diseases were regarded as negatively valent regions to be avoided." However, in applying the HBM to the prediction of contraceptive behavior, it is necessary to take into consideration the fact that pregnancy may be a positively-valued goal, even among young unmarried women for whom motherhood appears to be a socially-inappropriate role (Luker, 1975). Recognition of this fact does not, however, invalidate the $\mathrm{HBM}$ as an appropriate conceptual framework for the examination of contraceptive behavior (as suggested by Fisher, 1977 ), but simply requires that the possibility of an "approach" as well as an "avoidance" orientation toward pregnancy be incorporated into the model.

Perceived susceptibility. An analysis based on data from Kantner and Zelnik's 1971 sample of never-married sexually-active young women reports that "the dominant reasons cited for nonuse (of contraception) in some way or other discount the likelihood of conception" (Shah, Zelnik, \& Kantner, 1975). One study has illustrated the dramatic effects on perceived susceptibility and on subsequent contraceptive use of experiencing an actual pregnancy, as opposed to having had a pregnancy scare followed by a negative pregnancy test; after resolution of the pregnancy issue, the former group's use of contraception increased greatly, while the latter group continued not to use contraception "in the belief that they did not need it because they had not become pregnant the first time" (Evans, Selstad, \& Welcher, 1976).

Perceived seriousness. Shah et al. (1975) classified $16 \%$ of the unwed teenage girls in the Kantner and Zelnik sample who had had intercourse without using contraception as "wanting pregnancy." 
Of this $16 \%$, only one-third were actively trying to have a baby; the remainder "didn't mind" if they became pregnant. Among pregnant unmarried adolescent girls interviewed by Furstenberg (1976), about $20 \%$ were pleased to be pregnant; about the same proportion of a sexually-active but never-pregnant control group reported themselves at least somewhat receptive to the notion of becoming pregnant "in the next few months."

The major variables found to be associated with an attitude of relative equanimity toward the prospect of pregnancy are marriage plans (Shah et al., 1975) and low educational aspirations (Shah et al., 1975; Furstenberg, 1976). Ricketts (1973) reports a statistically significant, positive relationship between educational aspirations and contraceptive continuation rates.

\section{Estimates that Actions Will Achieve Goal}

Benefits of contraceptive use. Contraceptive use implies both some knowledge of contraceptive methods and some minimal level of confidence that the methods employed will be effective in preventing pregnancy. Studies report varying levels of contraceptive knowledge (Goldsmith, Gabrielson, Gabrielson, Mathews, \& Potts, 1972; Reichelt \& Werley, 1975; Furstenberg, 1976), and some skepticism about contraceptive efficacy, regardless of the method (Goldsmith et al., 1972). Focusing on a different dimension of "benefits," Reiss, Banwart, and Foreman (1975) found that college women who agreed that effective contraception can increase sexual enjoyment were more likely to attend a birth control clinic.

Barriers to contraceptive use.An essential distinction is that between barriers to the initial adoption of a contraceptive method and barriers to its continued use. One of the most frequently cited barriers to adoption of contraception by unmarried young women is based on what Fox (1973) terms the "nice girl" hypothesis: to start using a birth control method is to plan rationally for having intercourse, something that "nice girls" do not do [similar hypotheses have been advanced by Rains (1971) and Lindemann (1975)].

A second intrapersonal barrier to contraceptive use is that it is perceived as interfering with the "pleasure, spontaneity, or convenience" of sex (Shah et al., 1975). These "hedonistic" objections to contraception were voiced by $24 \%$ of respondents to 
the Kantner and Zelnik survey. While the "hedonistic" barrier is related to the "nice girls don' $t$ " barrier (both incorporate the rejection of rational planning for sex), the grounds for rejection are somewhat different.

The major reported barriers to continuation of a birth control method, among teenagers as among adults, are problems with the method: side effects that are experienced in conjunction with current use (nausea, pain, weight gain) and/or fear of future negative side effects (Furstenberg, 1976). It should be noted however, that because untoward "medical" complications are a legitimate reason for the discontinuation of any medicallyprescribed therapy, these reasons may be offered for discontinuation of medical methods even if other reasons are, in fact, more significant.

\section{Predisposing and Enabling Factors}

Lewinian field theory assumes that an individual's perceptions are greatly influenced by antecedent sociocultural heritage and accompanying socialization processes, while other variables may function as facilitator or inhibitors relevant to these propensities to act. This theoretical perspective was first designated "predisposing and enabling" factors by Andersen (1968) in his generic behavioral model of families' use of health services, and several classes of variables that have been identified in studies of contraceptive behavior logically belong in this category.

A wide variety of fertility-related attitudes have been used as predictors of contraceptive behavior. In recent studies focused on adolescent women's contraceptive use (Fox, 1977) and on contraceptive clinic attendance (Reiss et al., 1975), the most productive attitude scales measured respondents" "endorsement of sexual choice" (acceptance of premarital intercourse, abortion on demand, etc.) and nontraditional sex role attitudes. These attitudes may be presumed to influence the young woman's perceptions both of the consequences of pregnancy and of the benefits of contraception.

Finally, a number of investigators have emphasized the role of social support from friends, parents, or partners in encouraging the initiation and/or continuation of contraceptive use (Fisher, 1974; Luker, 1975; Bracken, 1977; Thompson \& Spanier, 1978; Fox, 1979). Based on her analysis of Furstenberg's data, Ricketts (1973) found 
that adolescent girls' perceptions of significant others' attitudes toward birth control has some effect on their contraceptive behavior.

\section{The "Adapted Health Belief Model"}

The preceding review indicates that a large number of the psychosocial variables found by previous investigators to be associated with teenagers' contraceptive behavior can be appropriately located within the HBM. This framework provides a basis for the logical ordering of previously-disconnected variables, and for their combined employment as predictors of contraceptive use. A revised version of the HBM is presented in Figure l; it focuses specifically on the prediction of adoption and continuation of contraceptive use by unmarried adolescent girls. In terms of this model, contraceptive adoption and continuation are hypothesized to be a function of three underlying variables: "threat" of pregnancy (incorporating perceived probability and perceived consequences of pregnancy), perceived benefits of contraception, and perceived barriers to contraception; these are determined, in turn, by cognitions, attitudes, and beliefs that are specific to pregnancy and to contraception. Each of these variables is listed under the appropriate heading in the model. In addition, the model incorporates a set of predisposing and enabling factors that are hypothesized both to influence and to be influenced by the three principal sets of variables.

\section{CONTRACEPTIVE ADOPTION: INTERPERSONAL VARIABLES}

Analysis of how the contraceptive-adoption process may be influenced by the providers of contraceptive services requires a major shift in theoretical perspective from a focus on psychosocial variables operating at the individual level to a concern with social interaction and social structure. Two assumptions underlie this change in emphasis: that provider influence is largely dependent upon the content and quality of interaction with contraceptiveseeking clients; and that these dimensions of provider-client interaction are, themselves, structurally limited by organizational constraints. This approach requires the theoretical framework for research to go beyond clients' subjective perceptions of the 
CONSTANCE A. NATHANSON AND MARSHALL H. BECKER

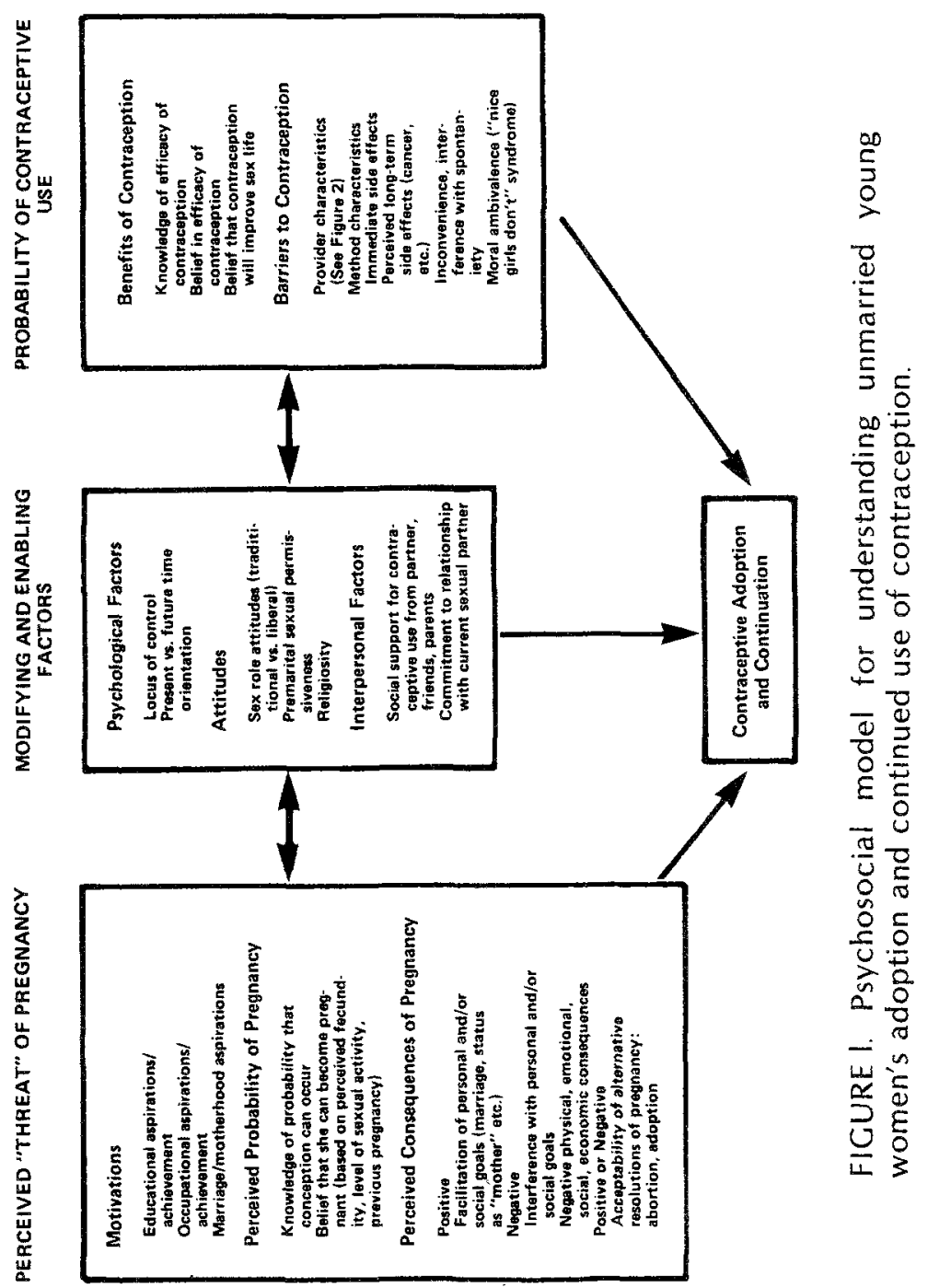




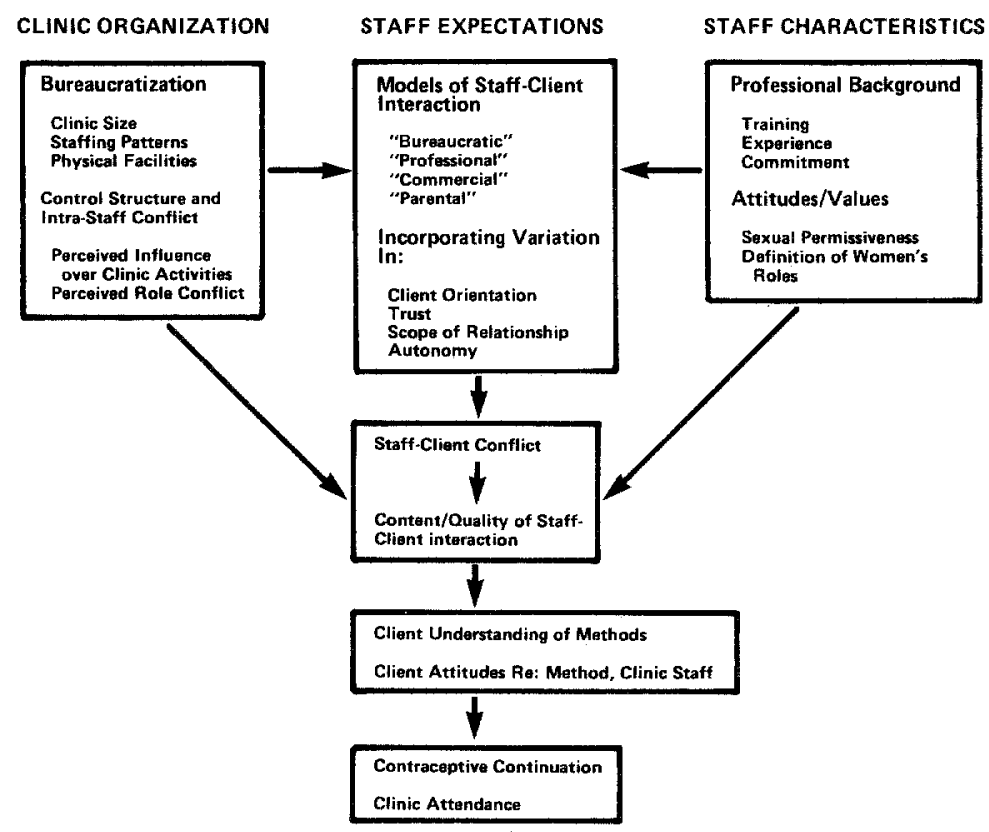

FIGURE 2. Model of structural variables for understanding young women's continued use of contraception.

providers/service organizations (which would fall under the "benefits" and "barriers" dimensions of the HBM), since it is necessary to assess the objective realities of the organization and its personnel (for example, size, staffing patterns, credentials and variety of personnel, number, scope and flexibility of rules, etc.), and the ways in which these variables influence the attitudes and behaviors of service providers. Comparing this information with client perceptions should permit more accurate prediction of contraceptive behaviors.

With the exception of Rogers' (1973) work on communication strategies, interpersonal and structural effects on the delivery of contraceptive services or on the adoption of contraceptive methods have received little attention in the family planning literature. Rogers, however, has identified the quality of "change agent-client interaction as a critical ingredient in family planning program effectiveness.

The approach to the analysis of client-provider interaction in organized family planning clinic settings presented here derives from the conflict-bargaining perspective proposed by Freidson 
(1961), Bloor and Horobin (1975) and others for the understanding of doctor-patient relationships. In this view, the conventional assumption of reciprocity in normative expectations between doctor and patient (and, by extension, between providers and clients generally) is open to serious question. It is proposed that interaction consists, instead, of "bargaining between interests based essentially on the structure of each role situation (that is, on the respective situations of professional and client)" (Bloom \& Wilson, 1979). Further " . . in that each (of the two parties) seeks to gain his own terms, there is conflict" (Friedson, 1961). Joffe suggests that the sources of conflict between providers and clients in service settings lie in their "different conceptions of what the services actually 'are' "(Joffe, 1979). The present analysis extends this conceptualization by proposing that the "conceptions" and "agendas" of clients and providers are based on a limited number of internalized "models" defining the nature of the anticipated transaction; insofar as these models fail to coincide, communication breakdowns between client and provider will occur, and client comprehension and/or acceptance of professional advice will be unpredictable.

There are at least four alternative models on which nurses, physicians, and teenage contraceptive clients might base their expectations: a "professional" model, as exemplified by the traditional doctor-patient relationship; a "bureaucratic" model, as exemplified by a welfare or employment office; a "commercial" model, as exemplified by the local drugstore, and a "parental" model, as exemplified by the relationship between mother and child. These models are not, of course, descriptions of empirical reality, rather, they are ideal-typical roles, sets of normative expectations on which individuals are hypothesized to pattern their behavior.

Three dimensions of difference among the models are pertinent to the present discussion. Probably the most important difference is in the expectations each model incorporates for control over the terms of the interaction: who will set these terms? How will compliance with these terms be obtained? Both the professional and the bureaucratic models assume that the terms of the relationship are largely set by the providers of service. However, the bases of expected compliance are distinctly different. Professional authority derives from the possession of specialized knowledge and skill; the client is expected to suspend his or her own judgment and to follow the advice of the expert-to 
"trust" the expert. Bureaucratic authority derives from the organizational role of the bureaucrat as gatekeeper, controlling access to services desired by the client. The terms of bureaucratic exchange are defined by impersonal rules and procedures; access to services is made conditional on client conformity with these rules and procedures. In contrast to both professional and bureaucratic models, the commercial model presupposes (in the ideal free-market case) client/customer control over the terms of exchange - "the customer is always right"; the only condition for participation in a commercial relationship is the customer's ability to pay. On the dimension of control, the parental model corresponds most closely to the professional model, although authority is an ascriptive characteristic of the parental role, and is not dependent on the possession of special qualities.

The parental model, however, contrasts sharply with the other three models on the two remaining dimensions of roleexpectations to be considered: the scope of the expected relationship and the degree to which it is characterized by affectivity vs. affective-neutrality (cf. Parsons, 1951). Parental interest in the child is expected to be diffuse, extending to all aspects of the child's life, rather than narrowly confined to a specific domain, and the parent-child relationship is expected to be highly affective-warm and personal rather than cool and impersonal. Although there may be some variation depending on circumstances, the general normative expectations for professional, bureaucratic, and commercial relationships are that they be specific rather than diffuse and that they be affectively neutral.

With the exception of the parental model, the models we have described are identical to the "paradigmatic modes of coping" identified by Friedson (1975) as characterizing the behavior of physicians in a group practice setting. We would argue that these models are more widely applicable, providing descriptions of available options for structuring staff-client interactions in service settings. Furthermore, we suggest that the models available to clinic staff are limited by structural constraints arising from relatively constant features of clinic organization and clinic ideology. Family planning clinics are bureaucracies with more or less fixed rules about who can receive what services under what conditions, and with more or less fixed procedures that clients are expected to follow. In addition, family planning clinics are staffed by professionals who are institutionally defined (and who define 
themselves) as experts in the field of contraception, and who are in control of the resources (effective contraceptive methods) desired by clients.

The considerations advanced above suggest that staff expectations for their own and clients' behavior are most likely to be based on some combination of bureaucratic and professional models. Prior research in family planning (Palmore \& Monsees, 1966; Urban and Rural Systems Associates, 1976) as well as in other health care settings (reviewed in Friedman \& DiMatteo, 1979) has emphasized the directly dysfunctional consequences for client outcomes of expectations based on bureaucratic or professional models (as opposed to warm, personal, client-oriented approaches). Rarely has consideration been given to the question of how staff expectations mesh with those of clients. Restatement of the issue in these terms redirects attention from a one-sided focus on the behavior of service providers (and an equally onesided emphasis on the desirability of particular modes of interaction) to a concern with the sources and consequences of staff-client conflict. We therefore hypothesize that agreement between staff and client on the terms of their interaction has a more significant impact on outcomes than does the specific model of interaction employed.

Predicting clients' expectations (particularly the expectations of teenage contraceptive clients) is more difficult than predicting expectations of staff, but potential sources of staff-client conflict can be readily identified. Perhaps the most obvious potential conflict is with clients who are operating in terms of the commercial (or "drugstore") model. Clients in this category enter the family planning clinic knowing what birth control method they want, and wanting it on their own terms. As a consequence, they may be quite reluctant to submit to required educational and counseling sessions (the principal vehicle for exercise of professional expertise in family planning clinics), and may be resistant to bureaucratic routines. Conflict arising from a very different source may occur with clients who base their expectations either on the conventional, professional (authoritarian) model of the doctor-patient relationship or, as may happen with very young teenagers, on the parental model. A central aspect of professional ideology in the family planning clinic setting is that clients should make their own contraceptive decisions, even "wrong" decisions, without interference based on the values of the professional (cf. Joffe, 1978). Clients who expect 
to be told what contraceptive method is best for them may find that their expectations conflict with the values of autonomy and responsibility espoused by clinic staff.

In addition to conflict arising from the divergent models on which clients and clinic staff base their respective expectations, conflict may also be produced if staff expectations of clients are internally inconsistent. An example of such inconsistency are simultaneous expectations for autonomy and compliance (also described by Bloor and Horobin [1975] as characterizing the doctor-patient relationship). The client is expected to display autonomy in selecting a contraceptive method, but also to abide by the clinic's terms for obtaining and using the method. Clients operating on the basis of the "drugstore" model conform with the first set of expectations but are less likely to conform with the second set.

The foregoing argument can be summarized very briefly. We propose that provider influence on clients' contraceptive behaviors (including contraceptive continuation and subsequent clinic attendance) will depend on the content (the cognitive component) and the quality (the affective component) of clientstaff interaction. It is hypothesized that conflict between the two parties to the contraceptive transaction will result in faulty communication on the level of content and/or on the level of the interest and concern conveyed by the staff to the client. Either type of communication breakdown can lead to subsequent problems in using the contraceptive method, to discontinuation of clinic attendance, and to short- or long-term discontinuation of contraceptive use. These are, of course, the most negative outcomes from the standpoint of contraceptive protection. Clients who have experienced communication problems at a particular clinic may simply change to another provider, switch to a nonmedical method, or do nothing. A teenager, however, may perceive fewer positive options than would an adult confronted with the same conflict situation. It is also possible that clients who have structured their expectations in terms of a bureaucratic model of interaction, but who encounter a "parental" nurse, will be happily surprised, with highly favorable consequences for their subsequent contraceptive behavior. The relative frequency of each alternative outcome we have described is, of course, an empirical question. However, given structural constraints on clinic staff (to which we have briefly referred), we would anticipate a high ratio of negative to positive outcomes of conflicting expectations. Based on the analysis presented, it can be further 
hypothesized that the degree of conflict between client and staff will depend both on the extent of divergence between their expectations and on the degree to which either clinic structure or their own inclinations will allow staff to set aside their own models and accommodate to the expectation and preferences of clients.

A model depicting the relationships proposed above is presented in Figure 2. A complete statement of relevant relationships would include sources of influence on both staff and client expectations. Although we have alluded to some of the factors that affect staff expectations in particular, space does not permit a detailed description of these factors.

\section{SUMMARY AND CONCLUSION}

This article has described a general theoretical framework for explaining contraceptive adoption and continuation among unmarried young women. The proposed framework has two major parts. The first part is focused on decision-making processes at the individual contraceptive-adopter level, and draws its explanatory variables from social-psychological theory adapted to the explanation of individuals' health-related behaviors. The second part takes account of those influences that arise in the course of interactions between the potential adopter and the providers of contraceptive methods, and draws its explanatory variables from structural and interactionist analyses of client-professional relationships. Figure 3 presents a diagrammatic attempt to bring these two perspectives together and to show how they may combine to influence the young woman's contraceptive behavior.

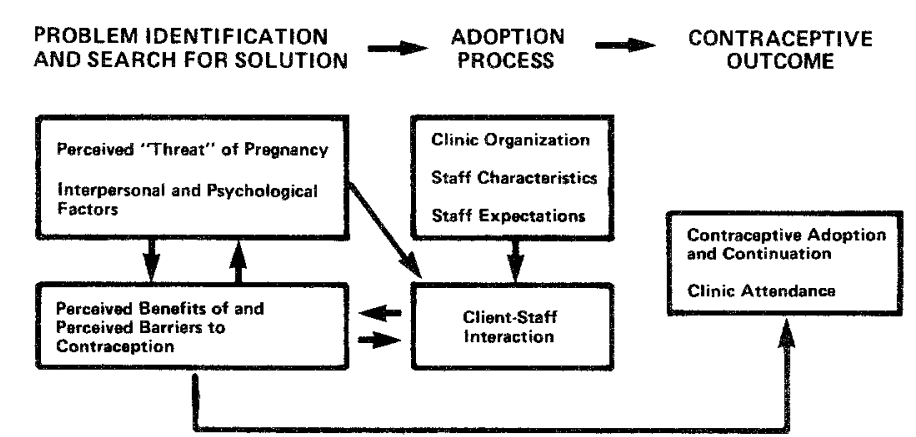

FIGURE 3. Combined theoretical framework for research on contraceptive behavior. 
At the level of psychosocial influences on contraceptive adoption and continuation, a number of significant departures from the original HBM are offered: (a) educational and occupational aspirations and achievements, and aspirations regarding marriage and motherhood, are included as motivational variables directly affecting the manner in which the "threat" of pregnancy is evaluated; (b) "perceived susceptibility" is expanded to include knowledge about probability of conception and other beliefs based on prior sexual experience; (c) recognizing that, for some women, pregnancy may be a desired goal, the conventional HBM's "perceived seriousness" is replaced by "perceived consequences," a dimension which specifies the different circumstances and perceptions that determine whether pregnancy will be positively or negatively valued; (d) "benefits is expanded to include the belief that use of contraception will improve sex life; (e) "barriers" is reformulated to incorporate both intrapersonal dimensions (such as moral ambivalence) and perceptions of interactions with service providers and organizations, and distinguishes between obstacles to initial adoption and barriers to contraception continuance; and (f) a "predisposing and enabling" category permits examination of important variables which act as antecedents and/or concomitants of subjective perceptions. The contributions of these psychological, attitudinal, and interpersonal factors to understanding contraceptive behaviors have been substantiated in the empirical literature.

Perhaps most important, however, is the complementary model proposed for viewing contraceptive adoption from the theoretical perspective of social structure and interaction. This new approach explicitly considers the objective characteristics of the service organization and its personnel, staff attitudes, and intrastaff interactions. Further, this conceptualization introduces four "models" of expectations which providers and clients bring to their interactions: "bureaucratic," "professional," "commercial," and "parental." Derived from a conflict-bargaining perspective, these models permit evaluation of staff-client interactions on the basis of extent of perceptual agreement along dimensions of "warmth" (affectivity), expected level of trust, desired scope of relationship, and decision-making autonomy with regard to contraception. It is suggested that the relative absence of consideration of these variables in attempts to explain 
contraceptive behavior (which, in the past, have tended to focus exclusively upon the individual adopter) represents a substantial deficiency in the available family planning literature.

Ultimately, influence is seen as being exerted through the perceptions and responses of the woman herself; however, these perceptions and responses are hypothesized to stem from both her own preexisting attitudes and characteristics and from her interaction with contraceptive providers. Whether and under what circumstances one set of variables has a more profound infuence on contraceptive behavior than the other is a question for future empirical research.

\section{REFERENCES}

Adler, N.E. Decision models in population research. Journal of Population, 1979, 2, 187-202. Akpom, C.A., Akpom, K.L. and Davis, M. Prior sexual behavior of teenagers attending rap sessions for the first time. Family Planning Perspectives, 1976, 8, 203-206.

Andersen, R. A Behavioral Model of Families' Use of Health Services. Research Series No. 25. Chicago: University of Chicago, Center for Health Administration Studies, 1968.

Becker, M.H., Haefner, D.P., Kasl, S.V., Kirscht, I.P., Maiman, L.A., \& Rosenstock, I.M. Selected psychological models and correlates of individual healthrelated behaviors. Medical Care, 1977, 15 (Supplement), 27-46.

Bloom, S.W. \& Wilson, R.N. Patient-practioner relationships In H.E. Freeman, S. Levine, abd L.G. Reeder (Eds.), Handbook of Medical Sociology (Third Edition). Englewood Cliffs: Prentice-Hall, 1979.

Bloor, M. I., \& Horobin, G.W. Conflict and Conflict resolution in doctor/patient interactions, 1Inc. Cox and A. Mead (Eds.), A Sociology of Medical Practice. London: Collier-MacMillan, 1975.

Bracken, $M$. Contraception and pregnancy after dropping out of family planning clinics: A national interview survey in Jamaica. Social Biology, 1976, 23, 55-56.

Bracken, M.B. The Jamaican family planning programme: Clinic services and social support as factors in dropping out. International Journal of Health Education, 1977, 20, 126-135.

Bracken, M. \& Kasl, S. Factors associated with dropping out of family planning clinics in Jamaica. American Journal of Public Health, 1973, 63, 262-271.

Card, J.J. \& Wise, L.L. Teenage mothers and teenage fathers: The impact of early childbearing on the parents' personal and professional lives. Family Planning Perspectives, $1978,10,199-205$.

D'Onofrio, C.A. Motivational and promotional factors associated with acceptance of a contraceptive method in the postpartum period. Doctoral dissertation, University of California at Berkeley, 1973.

Einhorn, R.F., Sear, A.M., Perez, E., \& Cabrera, E. Contraceptive method continuation 1according to type of provider. American Journal of Public Health, 1977, 67, 1157-1163.

Evans, J.R. Selstad, G., \& Welcher, W. Teenagers: Fertility control behavior and attitudes before and after abortion, childbearing, or negative pregnancy test. Family Planning Perspectives, 1976, 8, 192-200.

Fishbein, M. Toward an understanding of family planning behaviors. Journal of Applied Psychology, 1972, 2, 214-227. 
POPULATION AND ENVIRONMENT

Fishbein, M. \& Jaccard, J.J. Theoretical and methodological considerations in the prediction of family planning intentions and behavior. Representative Research in Social Psychology, 1973, 4, 37-51.

Fisher, A.A. Characteristics of family planning opinion leaders and their influences on contraceptive behavior of others. Doctoral dissertation, Johns Hopkins University, Baltimore, Maryland, 1974.

Fisher, A.A. The health belief model and contraceptive behavior: Limits to the application of a conceptual framework. Health Education Monographs, 1977, 5, 244-250.

Fox, G.L. Nice girl: The behavioral legacy of a value constuct. Paper presented at the annual meeting of the National Council of Family Relations, Toronto, 1973.

Fox, G.L. Sex-role attitudes as predictors of contraceptive use among unmarried university students. Sex Roles, 1977, 3, 265-283.

Fox, G.L. The Family's Role in Adolescent Sexual Behavior. Family Impact Seminar, George Wahington University, 1979.

Freidson, E. Patients' views of medical practice. New York: Russell Sage, 1961.

Freidson, E. Doctoring together: A study of professional social control. New York: Elsevier, 1975

Freidman, H.S. \& DiMatteo, M.R. Health care as an interpersonal process. Journal of Social Issues, 1979, 35, 1-12.

Fursternberg, F.F., Jr. Unplanned Parrenthood: The Social Consquences of Teenage Childbearing. New York: The Free Press, 1976.

Goldsmith, S., Gabrielson, M.O. Gabrielson, I., Mathews, V., \& Potts, L. Teenagers, sex, and contraception. Family Planning Perspectives, 1972, 4, 32-38.

Jaccard, J.\}. \& Davidson, A.R. Toward an understanding of family planning behaviors: An initial investigation. Journal of Applied Social Pscyhology, 1972, , 228-235.

Jaccard, J.J. \& Davidson, A.R. The relation of psychological, social, and economic variables to fertility-related decisions. Demography, 1976, 13, 329-338.

Joffe, C. Symbolic interactionism and the study of social services. Studies in Symbolic Interaction, 1979, 2, 235-256.

Karr, S.B. Individual aspirations as related to early and late acceptance of contraception Journal of Social Psychology, 1971, 83, 235-245.

Katatsky, M.E. The health belief model as a conceptual framework for explaining contraceptive compliance. Health Education Monographs, 1977, 5, 232-243.

Kothandapani, $V$. Validation of feeling, belief, and intention to act as three components of attitude and their contribution to prediction of contraceptive behavior. Journal of Personality and Social Psychology, 1971, 19, 321-333.

Lindemann, C. Birth Control and Unmarried Women. New York: Springer, 1975.

Luker, K. Taking chances: Abortion and the decision not to contracept. Berkeley: University of California Press, 1975.

Maiman, L.A. \& Becker, M.H. The health belief model: Origins and correlates in psychological theory. In M.H. Becker (Ed), The Health Belief Model and Personal Health Behavior. Thorofare, N.J.: Slack, 1974.

McCalister, D. \& Thiessen, V. Prediction in family planning: Prediction of the adoption and continued use of contraception. American Journal of Public Health, 1970, 60, $1372-1381$.

Nathanson, C.A. \& Morlock, L.L. Control structure, values and innovation: A comparative study of hospitals. Journal of Health and Social Behavior, 1980, 21, 315-333.

Palmore, J.A., Monsees, D.M. The Eastern Kentucky Private Physician. Plus Education Program. B. First evaluation of results. In D.J. Bogue (Ed.). The rural South fertility experiments. Chicago: University of Chicago, Community and and Family Study Center, 1966.

Parsons, T. The social system. Glencoe, Illinois: The Free Press, 1951

Phillips, J.F. Continued use of contraception among Philippine family planning acceptors: A multivariate analysis. Studies in Family Planning, 1978, 9. 182-192. 
CONSTANCE A. NATHANSON AND MARSHALL H. BECKER

Rains, P.M. Becoming an Unwed Mother. Chicago: Aldine, 1971.

Reichelt, P.A. \& Werley, H.H. Contraception, abortion, and venereal disease: Teenagers' knowledge and the effect of education. Family Planning Perspectives, 1975, 7, 83-88.

Reiss, I.L., Banwart, A. \& Foreman, H. Premarital contraceptive usage: A study and some theoretical explorations. Journal of Marriage and the Family, 1975, 37, 619-630.

Ricketts, S. Contraceptive use among teenage mothers: Evaluation of a family planning program. Doctoral dissertation, University of Pennsylvania, 1973.

Rogers, E.M. Communication Strategies for Family Planning. New York: The Free Press, 1971.

Rogers, E.M. \& Shoemaker, F.F. Communication of innovation. New York: Free Press, 1971.

Rosenstock, I.M. The health belief model and preventive health behavior. In M.H. Becker (Ed.), The health belief model and personal health behavior. Thorofare, N.J.: Slack, 1974.

Shah, F., Zelnik, M., \& Kantner, J.F. Unprotected intercourse among unwed teenagers. Family Planning Perspectives, 1975, 7, 39-44.

Suchman, E.A. Sociology and the Field of Public Health, New York: Russell Sage, 1963.

Thompson, L. \& Spanier, G.B. Influence of parents, peers, and partners on the contraceptive use of college men and women. Journal of Marriage and the Family, 1978, 40, 481-492.

Trussell, J. \& Menken, J. Early childbearing and subsequent fertility. Family

Planning Perspectives, 1978, 10, 209-218.

Urban and Rural Systems Associates. Improving family planning services for teenagers. Final Report submitted to office at Secretary for Planning and Evaluation/Health, DHEW, contract HEW OS-14-304. San Francisco: Author, 1976.

Zaltman, G. \& Lin, N. On the nature of innovations. American Behavioral Scientist, 1971, 14, $651-673$.

Zelnik, M. \& Kantner, J.F. Sexual activity, contraceptive use and pregnancy among metropolitan-area teenagers: 1971-1979. Family Planning Perspectives, 1980, 12, 230-237. 